\title{
The Immunosuppressant Protosappanin A Promotes Dendritic Cell-Mediated Expansion of Alloantigen- Specific Tregs and Prolongs Allograft Survival in Rats
}

\author{
Maomao Zhang ${ }^{1,29}$, Shuo Zhang ${ }^{1,29}$, Jian $\mathrm{Wu}^{1,29}$, Yong Sun ${ }^{2}$, Lili $\mathrm{Li}^{1,2}$, Wenjuan $\mathrm{Du}^{1,2}$, Jingjin Liu ${ }^{1,2}$, \\ Jingbo $\mathrm{Hou}^{1,2 *}$, Bo $\mathrm{Yu}^{1,2}$
}

1 The Key Laboratory of Myocardial Ischemia, Chinese Ministry of Education, Harbin, Heilongjiang Province, China, 2 Department of Cardiology, Second Affiliated Hospital of Harbin Medical University, Harbin, Heilongjiang Province, China

\begin{abstract}
Protosappanin A (PrA), an immunosuppressive ingredient of the medicinal herb Caesalpinia sappan L, prolongs heart allograft survival in rats, possibly by impairing the function of antigen-presenting cells (APCs). We examined the effects of PrA on the maturation and function of dendritic cells (DCs), a potent class of APCs, and the downstream cell-cell and intracellular signaling pathways mediating the immunosuppressive activity of PrA. PrA inhibited LPS-stimulated maturation of Wistar rat DCs in vitro as reflected by reduced expression of costimulatory molecules (CD80 and CD86) and reduced expression of TLR4 and NF- $\kappa B$, two critical signaling components for antigen recognition. PrA also enhanced the release of IL-10 and decreased the release of IL-12 from DCs, but had no effect on the production of TGF- 3 . In mixed cultures, Wistar DCs pretreated with PrA impaired the proliferation of Sprague Dawley (SD) rat T cells while promoting the expansion of SD rat $\mathrm{CD}^{+} \mathrm{CD} 25^{+}$regulatory T cells (Tregs). Both oral PrA treatment and infusion of PrA-pretreated Wistar DCs prolonged cardiac allograft survival (Wistar donor, SD recipient) and expanded recipient $\mathrm{CD} 4^{+} \mathrm{CD} 25^{+}$Foxp $3^{+}$Tregs. Donor spleen cells, but not spleen cells from a third rat strain (DA), supported the expansion of recipient $\mathrm{CD} 4^{+} \mathrm{CD} 25^{+}$Foxp $3^{+}$Tregs and suppressed recipient $\mathrm{T}$ cell proliferation. We conclude that PrA triggers a tolerogenic state in DCs that allows for the induction of alloantigen-specific Tregs and the suppression of allograft rejection in vivo.
\end{abstract}

Citation: Zhang M, Zhang S, Wu J, Sun Y, Li L, et al. (2013) The Immunosuppressant Protosappanin A Promotes Dendritic Cell-Mediated Expansion of AlloantigenSpecific Tregs and Prolongs Allograft Survival in Rats. PLoS ONE 8(6): e66336. doi:10.1371/journal.pone.0066336

Editor: Muriel Moser, Université Libre de Bruxelles, Belgium

Received December 20, 2012; Accepted May 3, 2013; Published June 26, 2013

Copyright: (c) 2013 Zhang et al. This is an open-access article distributed under the terms of the Creative Commons Attribution License, which permits unrestricted use, distribution, and reproduction in any medium, provided the original author and source are credited.

Funding: This work was supported by the National Natural Science Foundation of China (81200180), New Teachers' Fund for Doctor Stations, Ministry of Education (20122307120021), the Postdoctoral Foundation of China (2011M501065), Foundation of Heilongjiang Educational Committee (12531286), Key Laboratory of Myocardial Ischemia Mechanism and Treatment (Harbin Medical University, Ministry of Education, KF201001, KF201211), and the doctoral research fund of Second Affliated Hospital of Harbin Medical University (BS2011-18). The funders had no role in study design, data collection and analysis, decision to publish, or preparation of the manuscript.

Competing Interests: The authors have declared that no competing interests exist.

*E-mail: jingbohou@163.com

9 These authors contributed equally to this work.

\section{Introduction}

Protosappanin A ( $\operatorname{Pr} \mathrm{A})$, a potent immunosuppressive agent derived from the traditional medicinal herb Caesalpinia sappan $\mathrm{L}$, prolonged the survival of heart allografts in rat and prevented immune-mediated tissue damage $[1,2]$. Inhibition of acute tissue rejection was associated with reduced proliferation of recipient $\mathrm{T}$ cells and underexpression of $\mathrm{NF}-\kappa \mathrm{B}$ in infiltrating monocytes [3], but little is known of the intercellular and molecular signaling mechanisms for PrA-mediated immunosuppression.

An ideal clinical immunosuppsant for prevention of tissue rejection in transplant patients should impair only those antigen presenting cells (APCs) responsive to donor antigens [4]. Dendritic cells (DCs) are the most potent APCs and are thus a potential target for the induction of antigen-specific immunne tolerance. Indeed, DCs in an immunotolerant state expanded alloantigenspecific regulatory $\mathrm{T}$ cells (Tregs), while infusion of tolerogenic DCs prolonged allograft survival, likely by regulating the host $\mathrm{T}$ cell response [5-8].
In this study, we examined the effect of $\operatorname{PrA}$ on DC phenotype and compared the effects of native and PrA-treated DCs on the proliferation and phenotype of $\mathrm{T}$ cells to elucidate the signaling mechanisms of PrA-mediated immunosuppresion. PrA inhibited LPS-stimulated DG maturation, decreased DC TLR4/NF- $\kappa$ B expression and activity, induced $\mathrm{T}$-cell hyporesponsiveness, and expanded Tregs in vitro. Furthermore, PrA administration or transfer of PrA-treated donor DCs led to recipient $\mathrm{T}$ cell hyporesponsiveness and Treg expansion as well as suppression of allograft rejection in a rat model of heart transplantation. This study identifies the probable mechanisms for the immunosuppressive effect of PrA.

\section{Methods}

Experimental Animals

Specific pathogen free (SPF) male Wistar (recipient, 180-220 g), Sprague Dawley (SD, donor, 200-250 g), and DA rats (180$220 \mathrm{~g}$ ) were obtained from experimental animal center of Beijing for heart transplantation. The animals were maintained under 
standard conditions and fed rodent food and water according to the laboratory animal care principles and the guide for the care and use of laboratory animals in our institution.

\section{Drug preparation}

The heartwood of Caesalpinia sappan L was supplied by San Keshu Chinese Medical Market (Harbin, China) and the identity confirmed by the Pharmacy Faculty of HeiLongjiang University of Chinese Medicine.

The active $\operatorname{PrA}$ was extracted as described [1]. In brief, heartwood was soaked three times in 95\% ethanol and the PrA recovered from the ethanol by silica gel column chromatography. The isolated compound was identified by the specific wave spectrum and the purity shown to be more than 98\%. PrA was then dissolved in sterile distilled water to different concentrations for experiments.

\section{Generation of bone marrow-derived DCs and PrA treatment}

DCs were derived from the bone marrow precursors of Wistar rats as described previously [9]. Briefly, bone marrow was flushed from femurs and passed through a $100-\mathrm{mm}$ pore mesh to remove fibrous tissue. The red blood cells were lysed. Then the cells were cultured at $10^{6}$ cells $/ \mathrm{ml}$ in RPMI 1640 medium (HyClone, Logan, UT) supplemented with $10 \mathrm{ng} / \mathrm{ml}$ each of rat GM-CSF and IL-4 (PeproTech, Rocky Hill, NJ). To induce DG maturation, cells at day 6 in vitro were treated for $48 \mathrm{~h}$ with lipopolysaccharide (LPS, $10 \mathrm{ng} / \mathrm{ml}$; Sigma-Aldrich, St. Louis, MO). The DC phenotype was confirmed by anti-OX62 labeling and flow cytometry using a FACS Calibur system (detailed below). Only those preparations with a purity $>85 \%$ DCs were used for subsequent experiments. In other experiments, the DCs at day 6 were treated for $48 \mathrm{~h}$ with LPS plus different doses of PrA.

\section{Flow cytometry}

DC purity and phenotype were determined by surface expression of specific markers using flow cytometry. The following conjugated monoclonal antibodies (mAbs) were used: FITCOX62, PE-CD80, and PE-CD86 (eBioscience, San Diego, CA). For each staining protocol, the appropriate isotype-matched control was included.

For analysis of Treg expression phenotype, cells in mixed lymphocyte reactions (MLRs, prepared as described below) were washed twice with PBS and then stained for $30 \mathrm{~min}$ at $4^{\circ} \mathrm{C}$ with the following conjugated primary mAbs: CD4-FITC, CD25allophycocyanin, and Foxp3-PE (all from eBioscience). After primary antibody incubation, the cells were washed, fixed, permeabilized using fixation/permeabilization reagents (supplied by eBioscience), and stained for intracellular Foxp3. All reagents were used at optimal concentrations as determined by pilot experiments. Analysis of cell phenotype and cell counting were performed using FACS Calibur and analyzed using CellQuest Pro software.

\section{Cell viability}

Cell viability was assessed by the mitochondrial dehydrogenasedependent reduction of the yellow tetrazolium dye MTT to insoluble purple formazan. Cells were seeded at $0.5 \times 10^{6}$ cells $/$ well in 96-well plates and treated with different doses of $\operatorname{PrA}(0,5,20$, or $40 \mathrm{nM}$ ) for $48 \mathrm{~h}$. Following PrA treatment, $0.2 \mathrm{ml}$ of MTT stock solution $(5 \mathrm{mg} / \mathrm{ml}$, Sigma) was added to each well and the plates incubated for an additional $4 \mathrm{~h}$ at $37^{\circ} \mathrm{C}$. The supernatant was removed and $100 \mu \mathrm{l}$ of DMSO added to each well to dissolve the accumulated formazan. The absorbance at $570 \mathrm{~nm}$, indicative of viable cell number, was measured on a microplate reader. The assays were performed on at least three independent cultures and each PrA concentration was tested in triplicate within each microwell plate.

\section{Mixed lymphocyte response (MLR) assay}

Allogeneic $\mathrm{T}$ cells were isolated from SD rat spleens by nonadherence to nylon wool and cocultured at different plating ratios with Wistar DCs preactivated with LPS alone or LPS plus PrA to assess the impact of DC functional state on $\mathrm{T}$ cell proliferation and function. $1 \times 10^{6}$ isolated SD rat T cells were cultured for $5 \mathrm{~d}$ in 96well round-bottom microplates in the presence of Wistar DCs (control, LPS-treated, or LPS+PrA-treated; as stimulator) treated with the antimitotic agent mitomycin $\mathrm{C}(10 \mathrm{mg} / \mathrm{ml})$ at different DC:T cell ratios $(1: 10,1: 20,1: 50$, or 1:100). These cocultures were incubated with $10 \mathrm{mM} \mathrm{BrdU}$ for $24 \mathrm{~h}$, and $\mathrm{BrdU}$ incorporation by proliferating responder cells ( $\mathrm{T}$ cells) was quantified using a BrdU ELISA according to the manufacturer's instructions (Chemicon International, Temecula, CA). All proliferation assays were performed in triplicate.

To study the immunosuppressive effect of Tregs on $\mathrm{T}$ cell proliferation, $1 \times 10^{5} \mathrm{CD} 4^{+} \mathrm{CD} 25^{+}$Tregs isolated from MLRs by magnetic-activated cell sorting (MACS, detailed below) were added to the coculture of mitomycin C-treated spleen cells and allogeneic $\mathrm{T}$ cells at a Treg/T cell/spleen cells ratio of 10:10:1. The proliferation of $\mathrm{T}$ cells was again detected by BrdU-ELISA.

\section{Cell sorting by MACS}

The $\mathrm{CD} 4^{+} \mathrm{CD} 25^{+}$Tregs were isolated from cocultured MLRs by MACS [10,11]. First, CD $4^{+} \mathrm{T}$ cells were enriched by negative selection with anti-CD8 mouse IgG1 and anti-mouse IgGl microbeads (Miltenyi Biotec). Subsequently, the total CD $4^{+} \mathrm{T}$ cell population was incubated with anti-CD25 mouse IgG1 and antimouse $\mathrm{IgGl}$ microbeads, then separated into $\mathrm{CD} 4^{+} \mathrm{CD} 25^{+}$and $\mathrm{CD} 4^{+} \mathrm{CD} 25^{-} \mathrm{T}$ cell fractions by positive selection using an MS column (Miltenyi Biotec). The purity of $\mathrm{CD} 4^{+} \mathrm{CD} 25^{+} \mathrm{T}$ cells was consistently $80-90 \%$ as assessed by FACS (shown in Figure S1).

\section{Western blots}

Western blotting was used to assess TLR4 and NF-KB expression in DCs. Briefly, cell lysates were obtained after exposure of DC cultures to LPS (with or without $\operatorname{PrA}$ ) and blotted

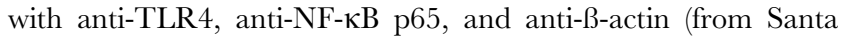
Cruz Biotechnology, Santa Cruz, CA). Target protein level was expressed as the densitometric ratio of target protein to B-actin.

\section{Immunofluorescence staining}

DCs grown on glass coverslips were fixed with 4\% paraformaldehyde for $30 \mathrm{~min}$ at room temperature, blocked with goat serum, and incubated with primary Abs against TLR4 or NF- $\kappa \mathrm{B}$ p65(1:100) overnight at $4^{\circ} \mathrm{C}$. After washing, cells were incubated with FITC-conjugated goat anti-mouse Ab (1:200; Santa Cruz Biotechnology) for $1 \mathrm{~h}$ at $37^{\circ} \mathrm{C}$. Nuclei were counterstained with DAPI $(0.1 \mathrm{~g} / \mathrm{ml}$; Sigma-Aldrich). Fluorescent images were acquired with a confocal laser-scanning microscope (FluoView v5.0 FV300; Olympus, Tokyo, Japan).

\section{Electrophoretic mobility shift assay (EMSA)}

Nuclear extracts of DGs were prepared with the nuclear extraction reagent (Pierce, Rockford, USA). Protein concentrations in the extracts were determined according to the Bradford assay (Bio-Rad, Hercules, CA, USA). To determine NF-кB 
activation, binding of NF- $\mathrm{B}$ p65 was assessed in nuclear extracts by EMSA [12]. Double-stranded oligonucleotides for NF- $\kappa \mathrm{B}$ p65 were labeled on the $3{ }^{\prime}$-end with biotin by using the $3^{\prime}$-Biotin endlabel kit from Pierce. EMSA was carried out by using the Lightshift kit from Pierce. Briefly, $10 \mu \mathrm{g}$ of nuclear protein were incubated for $20 \mathrm{~min}$ at room temperature with a biotin-labelled oligonucleotide probe (5'-AGT TGA GGG GAC TTT CGC AGG C-3'for the NF- $\kappa$ B binding site). Protein DNA complexes were separated by using a $6 \%$ nondenaturing acrylamide gel electrophoresis. The reactions were transferred to a nylon membrane. The biotin-labeled DNA was detected with LightShift chemiluminescent electrophoretic mobility shift assay kit (Pierce).

\section{Heart transplantation and PrA treatment}

Ectopic peritoneal heart transplantation was performed from Wistar to SD rats using the methods reported by Ono and Lindsey [13]. In brief, the ascending aorta and pulmonary artery of the donor heart were anastomosed bilaterally to the recipient abdominal aorta and inferior vena cava. Graft function was monitored by daily abdominal palpation and scored from 0 (no contractions) to 4 (vigorous contractions). Hearts were considered acutely rejected when the palpation score was $<1$. After heart transplantation, surviving animals were randomly divided into 3 groups. One group was given $25 \mathrm{mg} / \mathrm{kg}$ oral PrA every day from day 0 to 7 after transplantation, the second PrA-conditioned Wistar DCs at $2.5 \times 10^{6}$ cells per rat on days 1,3 , and 5 postsurgery, and the third with the same volume of PBS. Animal procedures were approved by the institutional Animal Ethics Committee of Harbin Medical University.

\section{ELISA analysis}

Cytokine levels in culture supernatant or rat serum were detected by two-site sandwich ELISA using antibody pairs against IL-12p70, IL-10 and TGF-B (R\&D Company, US). Samples were assayed in triplicate and were quantitated by comparison to standard curves generated using purified recombinant cytokines.

\section{Quantitative RT-PCR}

Briefly, total RNA was harvested from the cells, reversetranscribed to cDNA and amplified using SYBR Premix Ex Taq II (TaKaRa, Dalian, China) with primers. PCR amplification was performed for 30 cycles consisting of the following steps: 5 min at $94^{\circ} \mathrm{C}$ for denaturing, $30 \mathrm{~s}$ at the optimal temperatures specific to the primers used for annealing and $30 \mathrm{~s}$ at $72^{\circ} \mathrm{C}$ for extension. House-keeping gene of GAPDH was included as an internal control. All reactions were performed in triplicate. The expression of mRNA relative to GAPDH was determined using the $2^{-\Delta \Delta \mathrm{Ct}}$ method.

The following primers were used in this study: IL-12, forward, 5'-TGATGATGACCCTGTGCCTT-3' and reverse, 5'-GCATGGAGCAGGATACAGAGC-3'; IL-10, forward, 5'-CAGACGCACATGCTCGGAGA-3' and reverse, 5'-CAAGGCTTGGCAACGCAAGTA-3'; TGF- 3 , forward 5' - CTCAACACGTGCACAGGTCG-3', reverse 5'-ACGATCATGTTGGACAACTGCT-3'; GAPDH, forward, 5'-TTCA TTGACGTCAACTAC-3' ${ }^{\prime}$, reverse, 5' -AGACTCGACGACATACTC-3'

\section{Statistical analyses}

Data is expressed as mean \pm standard error of the mean. Differences between nonparametric data sets were examined by the Mann-Whitney test. Multiple group means were compared by one-way ANOVA. Differences were considered statistically significant at $\mathrm{P}<0.05$.

\section{Results}

\section{PrA suppressed LPS-induced DC maturation}

We first determined the non-toxic dose range of PrA for DCs in vitro using the MTT assay. Addition of PrA at $40 \mathrm{nM}$ significantly decreased DC viability compared to control cultures $(\mathrm{P}<0.05)$ while lower doses did not (Fig. 1A). In subsequent experiments, $5 \mathrm{nM}$ and $20 \mathrm{nM}$ doses were used to examine the mechanisms of PrA-induced immunosuppression.

Immature DCs can be induced to mature by stimulation with LPS and is accompanied by increased surface expression of the costimulatory molecules CD80 and CD86. We investigated whether DCs treated with PrA still expressed these surface markers after activation by LPS. DCs cultured with the cytokines GM-CSF and IL-4 for 6 days were stimulated with LPS alone $(10 \mathrm{ng} / \mathrm{ml})$ or LPS plus $\operatorname{PrA}$ and cultured for an additional $48 \mathrm{~h}$. After LPS stimulation, the levels of CD80 and CD86 were significantly higher in LPS-treated DCs (LPS-DC) compared with imDCs without LPS condition as indicated by flow cytometry. However cells pretreated with $\operatorname{PrA}(20 \mathrm{nM})$ plus LPS expressed markedly lower levels of CD80 and CD86 than DCs treated with LPS alone (LPS-DC). The difference of CD80 and CD86 expression between DCs treated with $20 \mathrm{nM}$ PrA plus LPS (20-DC) group and imDG group was not statistical significant (Fig. 1B, C, D). The results suggested that $\operatorname{PrA}$ at a non-toxic dose $(20 \mathrm{nM})$ impeded LPSstimulated DC maturation as defined by surface CD80 and CD86 expression.

The effects of PrA on DC function were examined in cocultures containing Wistar-derived DCs and allogeneic $\mathrm{T}$ cells isolated from SD rat spleen (MLRs). Activated DCs normally induce allogeneic $\mathrm{T}$ cell proliferation; however, $\mathrm{T}$ cells from SD rats exhibited a reduced proliferative response in the presence of activated DCs pretreated with PrA compared to T cells cultured with PrA-naïve activated DCs (Fig. 1E). PrA-conditioned DCs not only depressed the allogeneic $\mathrm{T}$ cells proliferation, but also modulated the cytokines secretion in MLR cocultures with a higher IL-10 production and lower IL-12 production (Fig. 1F, G). Therefore, the capacity of LPS-stimulated DCs to undergo functional maturation was also inhibited by $\operatorname{PrA}$.

\section{DCs pretreated with PrA enhanced the proliferation of Tregs in MLRs}

To determine if Tregs were induced by PrA-treated DCs, the expression levels of the Treg surface markers CD4, CD25 and Foxp3 were examined by FACS in cocultures of Wistar DCs and SD-derived T cells. Tregs expressing CD4, CD25 and Foxp3 were significantly expanded in cocultures containing PrA-pretreated DCs compared to cocultures containing PrA-naïve DCs (Fig. 2A, B). We then assessed the effects of PrA-pretreated DCs on Treg function by measuring Treg immunosuppressive capacity on $\mathrm{T}$ cells. It is known that $\mathrm{CD} 4^{+} \mathrm{CD} 25^{+}$Tregs normally suppress $\mathrm{T}$ cell proliferation, so we separated $\mathrm{CD} 4{ }^{+} \mathrm{CD} 25^{+}$Tregs from the mixture of DCs (PrA-treated or PrA-naïve) and T cells by MACS, and then cocultured these $\mathrm{CD} 4{ }^{+} \mathrm{CD} 25^{+}$Tregs (suppressors) with SD-derived $\mathrm{T}$ cells (responders) and Wistar spleen cells treated with mitomycin C (stimulators) at a Treg:T cell:spleen cells ratio of 10:10:1. The proliferation of responder $\mathrm{T}$ cells by allogeneic spleen cells was suppressed by the addition of Tregs induced by PrA-pretreated DCs compared to Tregs induced by PrA-naïve DCs and the reduction in $\mathrm{T}$ cell proliferation was dependent on the PrA dose (Fig. 2C).

In order to determine if Tregs in MLRs mediated alloantigenspecific inhibition, DA rat spleen cells were used instead as a source of stimulator cells. In contrast to Wistar-derived stimula- 
A
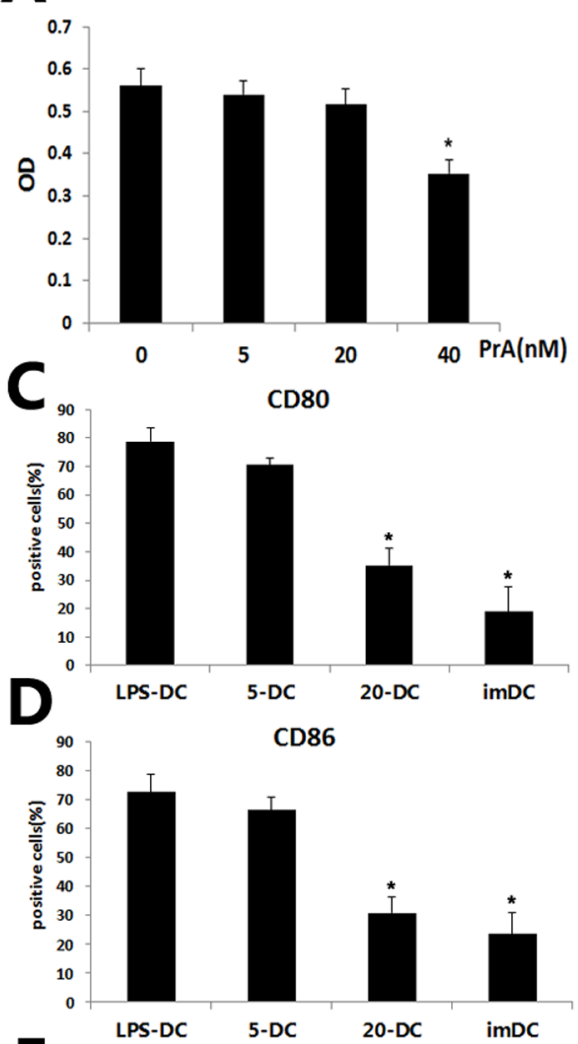

$\mathbf{E}$

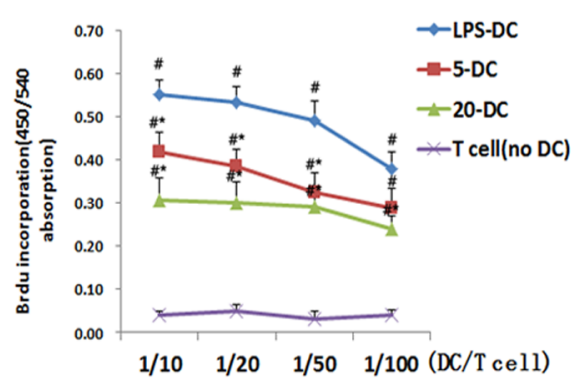

B

LPS-DC
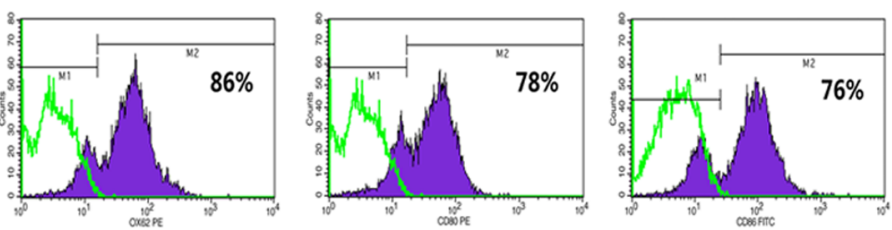

5-DC
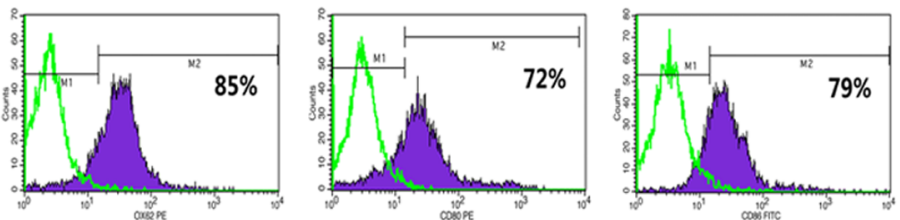

20-DC
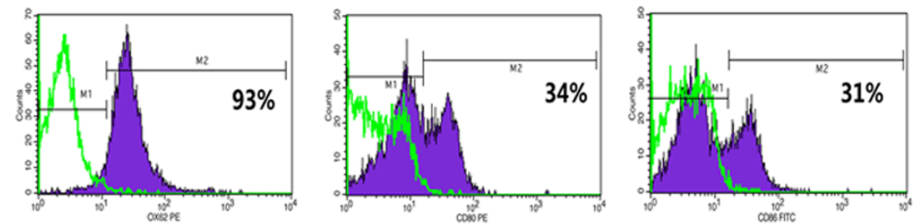

im-DC

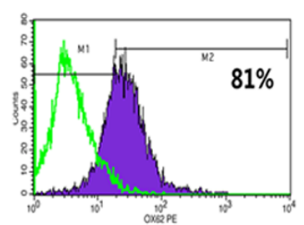

0X62

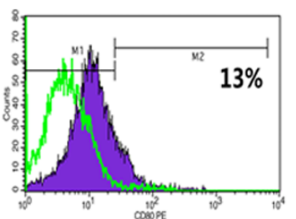

CD80
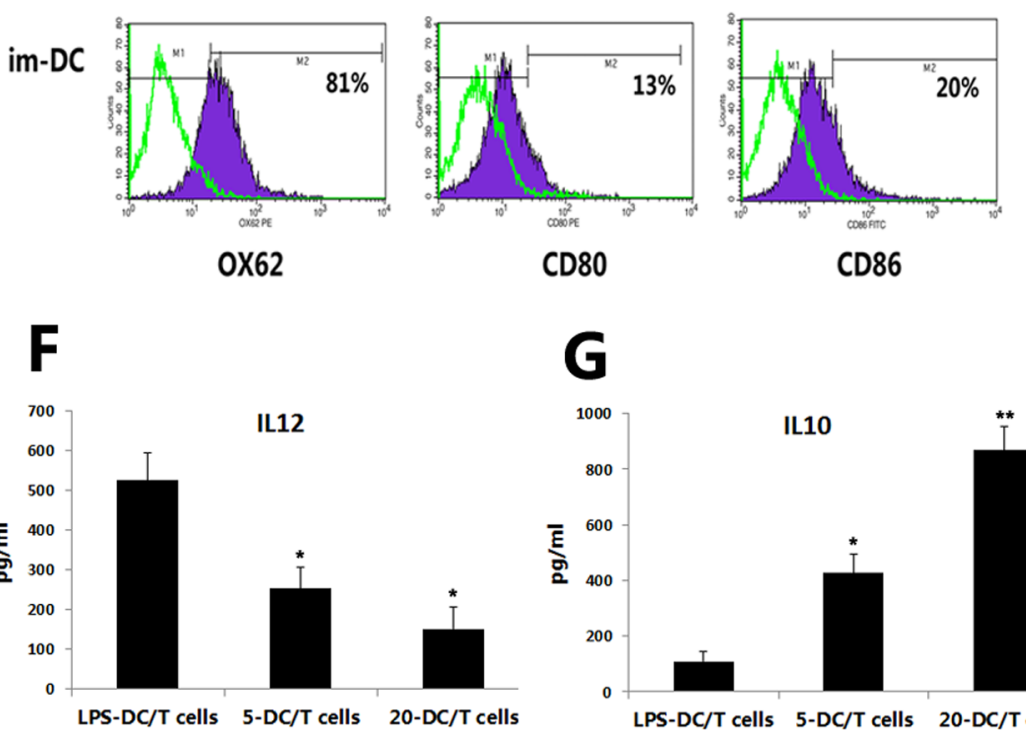

Figure 1. PrA inhibited DC maturation responding to LPS and diminished DC-mediated T cell allostimulation. DCs (Wistar) were treated with LPS alone or LPS plus PrA (5, 20, or $40 \mathrm{nM}$ ) from days 7 to 9 in vitro. (A) DC viability was measured at each concentration using the MTT assay. The highest dose induced a significant decrease in viable DC count, so only $5 \mathrm{nM}$ and $20 \mathrm{nM}$ were used in subsequent experiments. (B, C, D) LPS-induced maturation of DCs was examined by immunolabeling for OX62, CD80, and CD86 and subsequent FACS. Treatment with PrA suppressed the LPS-stimulated expression of these DC markers. (E) The proliferation of SD T cells in MLR coculture with mitomycin C-pretreated Wistar DCs (as stimulator) at DC:T plating ratios of 1:10, 1:20, 1:50, and 1:100 was measured by Brdu incorporation. PrA-treated DC displayed much inferior T cell allostimulatory activity in MLR using $1 \times 10^{6}$ SD T cells as responders. $(F, G)$ IL-12p70 and IL-10 production in MLR coculture supernatant (DC and T cells ratio of 1:10) were assessed by ELISA. Data are shown as the means \pm SD of three independent experiments $(A, C-G ; n=3)$. Similar results were obtained in three independent experiments $(B ; n=3)$. ${ }^{*} P<0.05$ and ${ }^{* *} \mathrm{P}<0.01$ compared with the LPS-DC (no $\left.\operatorname{Pr} A\right)$ control group. ${ }^{\#} \mathrm{P}<0.05$, compared with the T cells only (no DC) group.

doi:10.1371/journal.pone.0066336.g001

tors, proliferation of SD-derived T cells in response to DA ("third party") stimulator spleen cells was not affected by the addition of SD-derived Tregs induced by PrA-pretreated Wistar DCs (Fig. 2D). Tregs have been demonstrated to be able to produce both suppressive cytokines IL-10 and TGF- $\beta$, so we measured IL10 and TGF- $\beta$ mRNA expression in MACS-sorted $\mathrm{CD} 4{ }^{+} \mathrm{CD} 25^{+}$Tregs to determine whether it is modulated by $\operatorname{PrA}$. As shown in Fig. 2E-F, we found that only IL-10 mRNA level was significantly up-regulated in Tregs induced by the PrA-conditioned DCs, compared with Tregs induced by PrA naïve LPS-DGs assessed by qRT-PCR. The results indicated that the elevated IL10 level, but not TGF- $\beta$, may contribute to the functional capacity of Tregs primed by PrA-conditioned DCs and be implicated in the immunosuppressive mechanism of PrA. Collectively, our findings thus far suggest that PrA-conditioned DCs adopt an immunotolerant phenotype that supports the expansion of Tregs with antigen-specific immunosuppressive effects. 

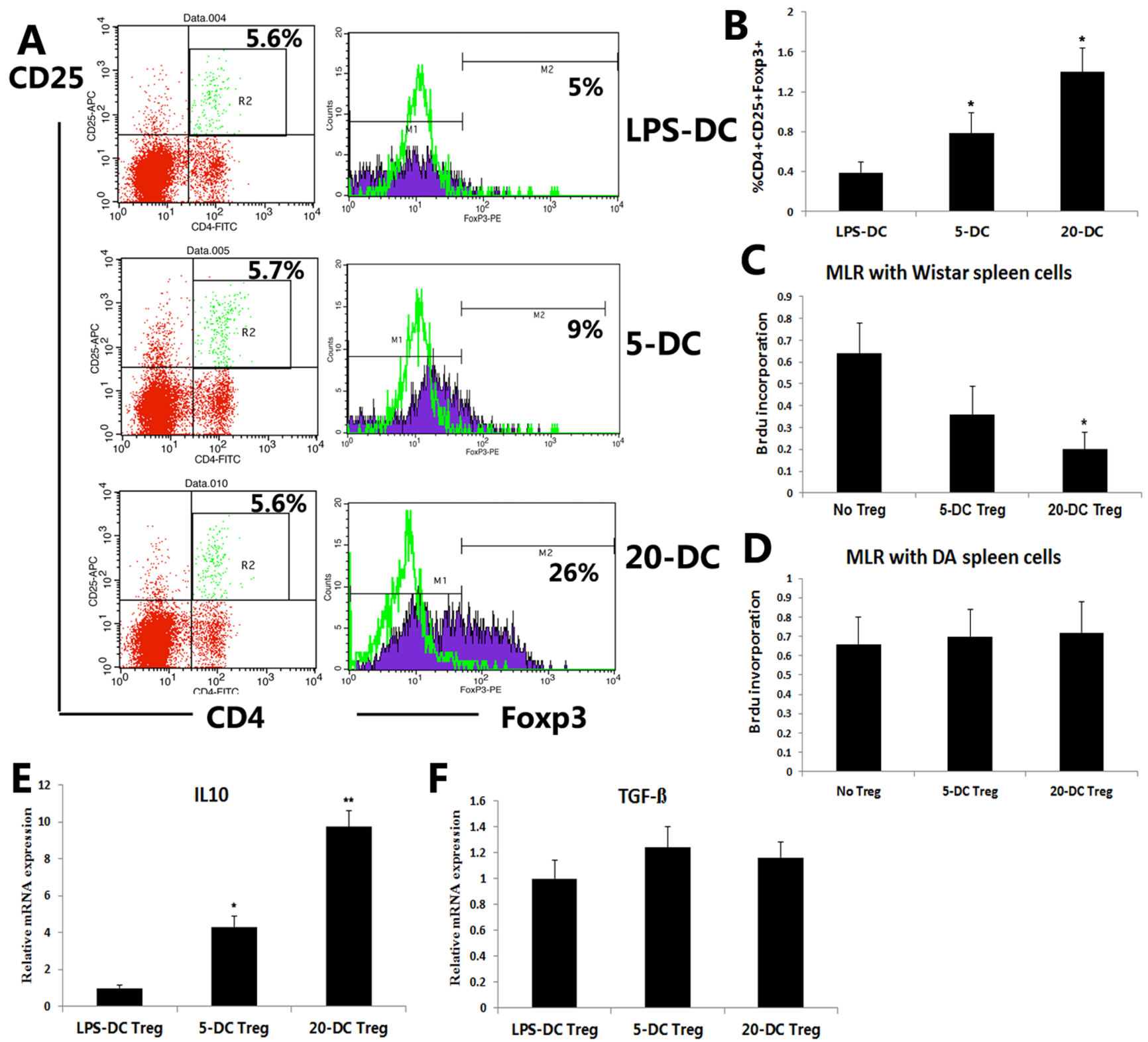

$\mathbf{F}$

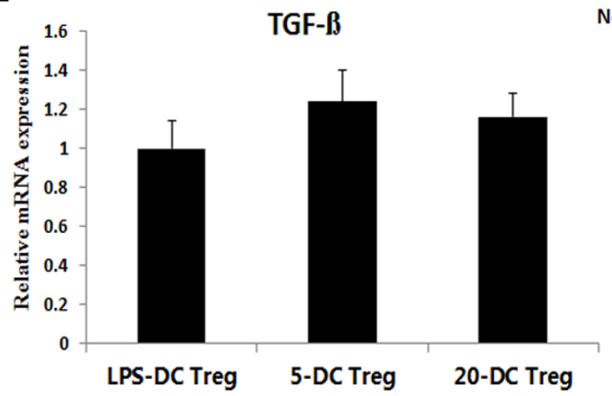

MLR with DA spleen cells

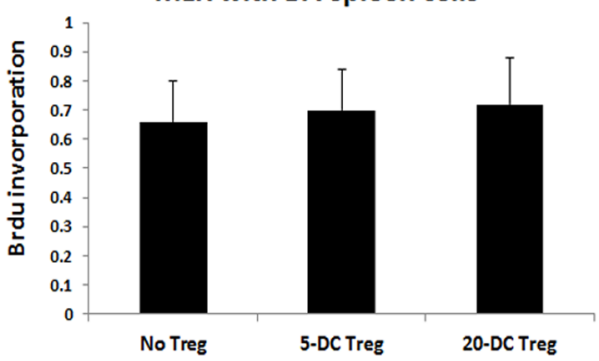

Figure 2. PrA-pretreated DCs induced the expansion of antigen-specific Tregs. (A, B) SD-derived T cells were cocultured with mitomycin Cpretreated Wistar DCs (with LPS or LPS plus PrA) for 2 days. Expression levels of the Treg markers CD4, CD25, and Foxp3 in coculture were measured by FACS. PrA-treated DC induced CD4 $4^{+} \mathrm{CD} 25^{+} \mathrm{Foxp}^{+}{ }^{+}$Tregs expansion in a dose dependent manner. (C, D) SD-derived $\mathrm{CD} 4^{+} \mathrm{CD} 25^{+}{ }^{+}$Tregs were isolated from coculture with Wistar DCs by MACS and added to MLRs containing SD-derived T cells (responders). Either Wistar rat spleen cells or DA rat spleen cells ("third party" cells) were used as stimulator cells in these MLRs at a Treg:T cell:spleen cells ratio of 10:10:1. SD Tregs derived from $20 \mathrm{nM}$ PrApretreated Wistar DC cocultures suppressed SD T cell proliferation (as evidence by reduced Brdu incorporation) compared to SD Tregs derived from PrA-naïve DC cocultures in the presence of Wistar spleen cells but not in the presence of DA (third party) spleen cells. (E, F) IL-10 and TGF- $\beta$ mRNA levels in these sortedTregs induced by DCs with or without PrA condition were assessed by qRT-PCR. Data are shown as the means \pm SD of three independent experiments $(B-F ; n=3)$. Similar results were obtained in three independent experiments $(A ; n=3)$. ${ }^{*}<<0.05$ compared to LPS-treated PrA-naïve DC controls.

doi:10.1371/journal.pone.0066336.g002

\section{PrA regulated the production of IL-10 and IL-12 by DCs in response to LPS}

Different cytokines act as pro-inflammatory or anti-inflammatory mediators, so the DC cytokine expression/secretion profile is one of the ultimate determinants of functional status. To investigate the effect of $\operatorname{PrA}$ on the cytokine secretion profile of DGs, the cytokine levels in culture supernatants and the mRNA levels in DCs were measured using ELISA assays and qRT-PCR. IL-10 and TGF- 3 are key differentiation factors for the selection and effector function of Tregs; therefore, we compared the production of IL-10 and TGF-B by PrA-treated and PrA-naïve DGs after LPS stimulation assessed by ELISA and qRT-PGR. Consistent with the immunotolerant phenotype induced by PrA, PrA-treated DCs produce more IL-10 secretion and mRNA expression than PrA-naive DCs and this IL-10 production increased with the PrA dose (Fig. 3B, E). Concomitant with the increase in IL-10 secretion, we observed a PrA dose-dependent decrease in IL-12 release and mRNA expression from DCs 
A

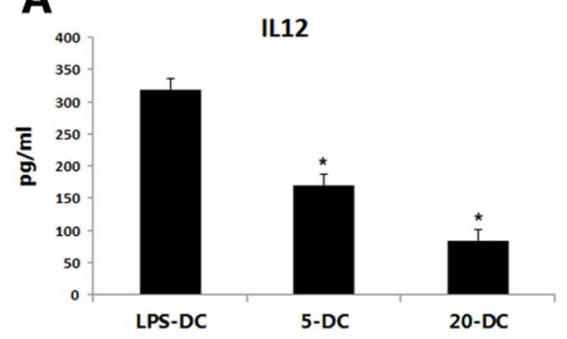

D

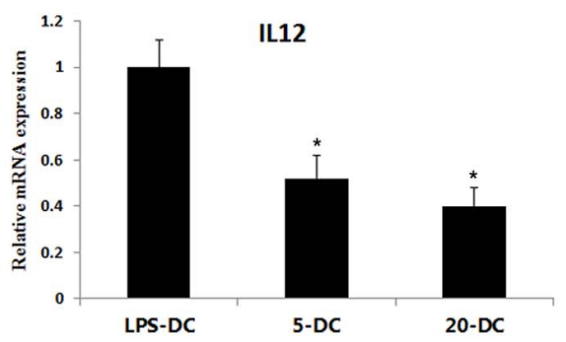

B

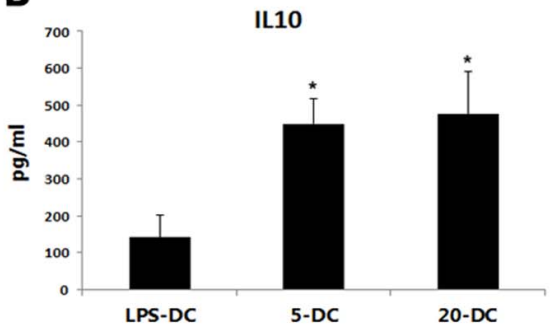

$\mathbf{E}$

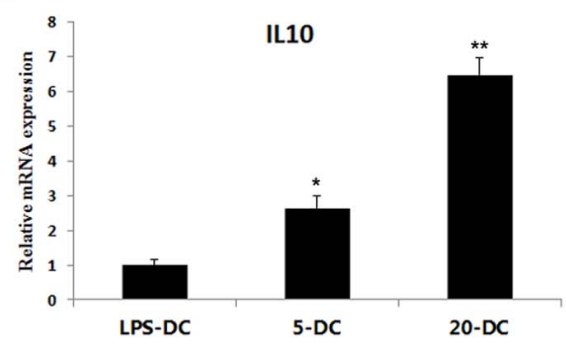

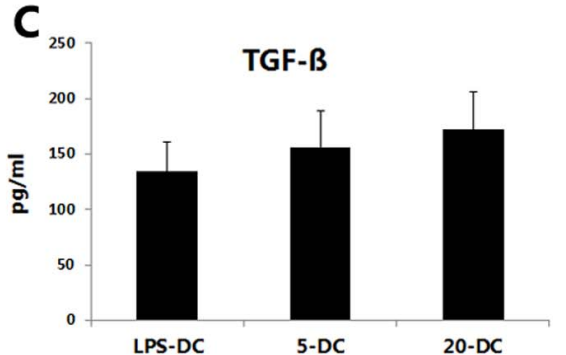

$\mathbf{F}$

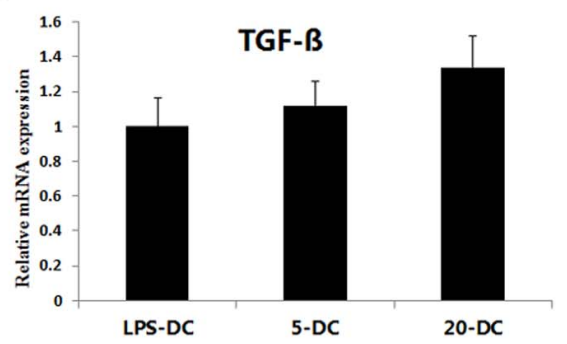

Figure 3. PrA modulated the IL-10 and IL-12 production of DCs responding to LPS. DCs were treated with LPS alone or LPS plus PrA (5 or $20 \mathrm{nM}$ ) from days 7 to 9 in vitro. The cytokines secretion and mRNA expression in DCs were assessed by ELISA and qRT-PCR. PrA suppressed IL-12p70 release (A) and mRNA level (D) from cultured Wistar DCs, accompanied with enhanced IL-10 release (B) and mRNA level (E). However PrA condition had no significant effect on TGF- $\beta$ production of DCs $(C, F)$. The results are means \pm SE of three independent experiments $(n=3)$. ${ }^{*} P<0.05$, **P<0.01 compared to LPS-DC controls.

doi:10.1371/journal.pone.0066336.g003

(Fig. 3A, D). However neither secretion nor the mRNA level for TGF- $\beta$ showed a significant difference between the experimental groups (Fig. 3C, F), suggesting that TGF-B might not be implicated in the immunosuppressive mechanism of $\operatorname{PrA}$.

\section{PrA reduced the expression of TLR-4 and NF- $\kappa B$ by DCs}

The pattern recognition receptor family toll-like receptors (TLRs) contribute to antigen uptake, processing, and presentation. Toll-like receptor 4 (TLR4) plays a particularly crucial role in LPS-mediated DC activation. Expression of TLR4 and NF- $\kappa \mathrm{B}$ by DGs was decreased in a dose-dependent manner by $\operatorname{PrA}$ as indicated by both Western blotting (Fig. 4A, B) and immunostaining of DCs (Fig. 4G). The NF- $\kappa \mathrm{B}$ activation of DCs responding to LPS was also depressed by PrA condition as assessed by EMSA (Fig. 4D). Therefore, PrA might modulate DC function at least partially by depressing TLR4/NF- $\mathrm{KB}$ signaling.

\section{Injection of PrA-treated DCs promoted cardiac allograft survival}

We previously demonstrated that PrA administration prolonged cardiac allograft survival and inhibited $\mathrm{T}$ cell proliferation, while the current in vitro studies revealed that PrA-pretreated DCs suppressed T cell proliferation, promoted Treg expansion, and enhanced the immunosuppressive capacity of Tregs on T cells. Thus, PrA may promote allograft survival through similar effects on immune effector cells in vivo. We first compared the survival of hearts from Wistar donors in SD recipients administered vehicle, PrA, or infused with PrAconditioned Wistar DGs after transplant. Ten recipient rats were injected intravenously with $2.5 \times 10^{6} \mathrm{PrA}$-treated DCs $(\mathrm{n}=10)$ on days 1,3 , and 5 postsurgery while ten recipients were injected with the same volume of PBS $(n=10)$ on days 1,3 , and 5 . The other ten rats were administered $25 \mathrm{mg} \cdot \mathrm{kg}^{-1} \operatorname{PrA}$ os every day $(\mathrm{n}=10)$ from day 0 to 7 after transplantation. Both infusion of PrA-treated Wistar DCs and PrA administration prolonged graft survival compared to the PBSinjected controls (Fig. 5A).
PrA induced the expansion of Tregs exhibiting alloantigen-specific immunosuppression in recipient rats

We investigated whether PrA induce the expansion of Tregs after transplantation by measuring CD4, CD25, and Foxp3 expression in the spleens of the three recipient groups. Consistent with in vitro results, recipient rats injected with PrA-treated DCs or treated with PrA exhibited a significant increase in the $\mathrm{CD} 4^{+} \mathrm{CD} 25^{+}$Foxp $^{+}$Treg population compared to recipient rats receiving only PBS (Fig. 5B, C).

To assess the immunosuppressive activity and antigen specificity of Tregs in recipient rats, we measured the proliferation of recipient (SD rat) $\mathrm{T}$ cells in the presence of mitomycin C-treated donor (Wistar rat) spleen cells or "third party" spleen cells from DA rats. Consistent with in vitro results, spleen cells from recipients administered either PrA or PrA-treated DCs showed reduced $\mathrm{T}$ cell proliferation compared to spleen cells from PBStreated control recipients. In contrast, no reduction in $\mathrm{T}$ cell proliferation was observed when cocultured with third party spleen cells from DA rats treated with PrA or infused with PrA-treated DCs (Fig. 5D, E). These results strongly suggest that Tregs induced by PrA-treated DCs in vivo also exhibit donor-specific immunosuppression.

Finally, we also measured IL-10, IL-12 and TGF- $\beta$ concentrations in serum by ELISA and observed depressed IL-12 production (Fig. 6A) and increased IL-10 production (Fig. 6B) in the PrA-treated DC and PrA groups (both $\mathrm{P}<0.05)$ compared to the PBS control group, except for TGF-B production (Fig. 6C). These findings were consistent with in vitro results and suggesting that PrA induces tolerogenic DCs in vivo.

\section{Discussion}

Conventional immunosuppressants that inhibit $\mathrm{T}$ cell activity prevent rejection after transplantation. However, these agents impair both $\mathrm{T}$ cells targeting donor antigens and those that protect against microorganisms, increasing the risk of postoperative 
A

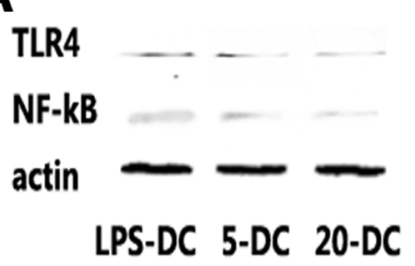

B

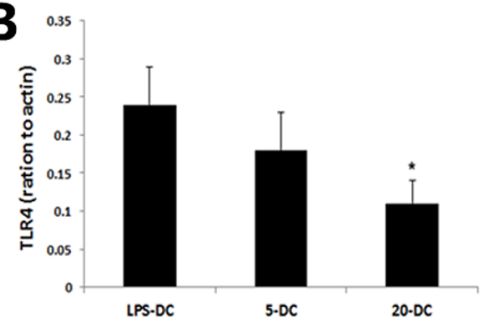

C

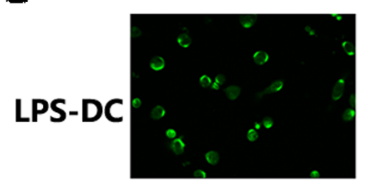

20-DC

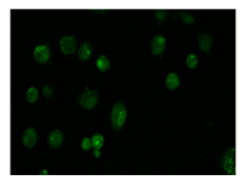

DAPI
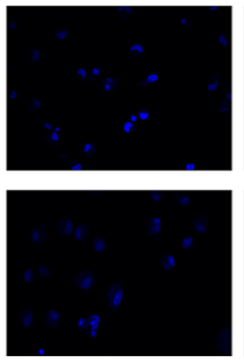

Merged
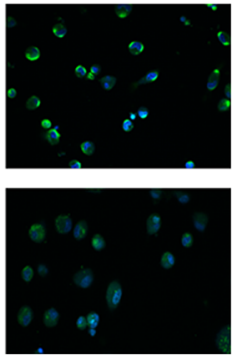

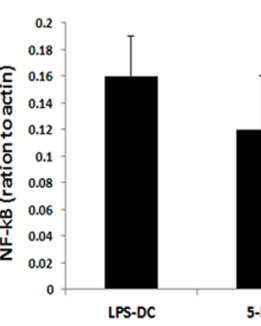

NF-kB

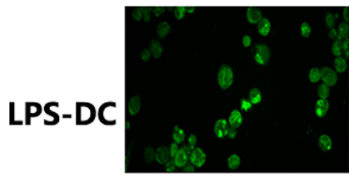

20-DC

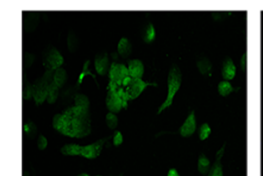

D
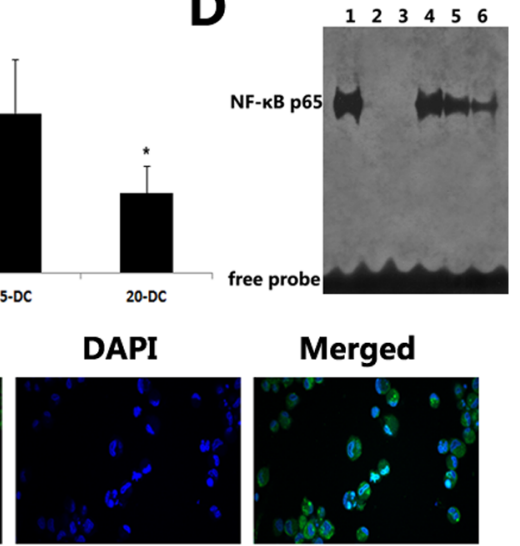

Merged

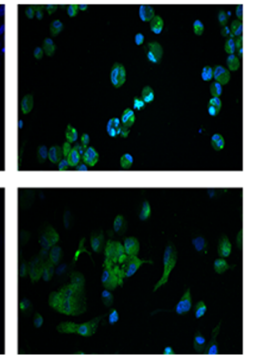

Figure 4. PrA suppressed TLR4 and NF-kB protein expression by DCs. DCs were exposed to PrA (0, 5 , or $20 \mathrm{nM})$ and stimulated with LPS

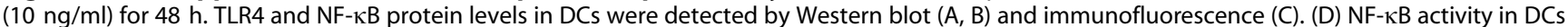
responding to LPS was depressed by PrA assessed by EMSA. Lane 1: positive nuclear extracts control containing active NF- $\mathrm{B}$; lane 2: negative nuclear extracts control without containing active NF-KB; lane 3: free oligonucleotide probe only; lane 4: LPS-DC; lane 5: 5-DC; lane 6: 20-DC. Data are shown as the means $\pm S D$ of three independent experiments $(B ; n=3)$. Similar results were obtained in three independent experiments $(A, C$, $D$; $\mathrm{n}=3)^{*} \mathrm{P}<0.05$ compared to LPS-DC controls.

doi:10.1371/journal.pone.0066336.g004

infection. An ideal immunosuppressant would impair only those APCs that respond specifically to donor antigens while not interfering with other immunological processes. Our previous studies demonstrated that PrA, an active component of Caesalpinia sappan L, promoted cardiac graft survival [1] and suppressed infiltrating $\mathrm{T}$ cell activity by inhibiting NF- $\kappa \mathrm{B}$ activity [2]. In this study, we elucidated the cellular and molecular signaling pathways mediating this immunosuppressive effect. Of greater significance, we demonstrate that PrA acts to suppress immunity against donor antigens but not against third party antigens, suggesting that this compound may prevent post-transplantation rejection while maintaining immune protection against infection.

Dendritic cells are potent stimulators of naive $\mathrm{T}$ cells and key inducers of primary immune responses, including transplant immunity [4]. To identify the mechanisms of PrA-mediated immunosuppression, we examined the effects of this compound on DC maturation and of PrA-treated DGs on T cell and Treg functions. We demonstrate that PrA inhibits LPS-stimulated DC maturation, as evidence by the down-regulation of costimulatory molecules, and reduces the capacity of activated DC to stimulate $\mathrm{T}$ cell proliferation.

Dendritic cells can either activate $\mathrm{T}$ cells or induce $\mathrm{T}$-cell tolerance depending on the state of maturation. Tolerogenic DGs in a CD80 CD86" "immature" state reduce T cell proliferation and promote Treg differentiation [8,14-17]. Indeed, the potential use of immature DCs as a cell-based therapy to promote immune tolerance following organ transplantation has been an area of active research, and transfer of immature DCs has been shown to act synergistically with pharmacotherapy to promote long-term allograft survival [7,18-22]. In this study, we found that $\operatorname{PrA}$ induced a functional state that conferred the capacity to expand Tregs and induce an immunosuppressive $\left(\mathrm{CD} 4^{+} \mathrm{CD} 25^{+}\right)$Treg phenotype. Moreover, transfer of PrA-treated DCs promoted graft survival and induced Treg expansion in vivo, further confirming that PrA may act directly on DCs to enhance allograft immunity.
Regulatory $\mathrm{T}$ cells have crucial roles in maintaining tolerance and modulating adaptive immune responses. Accumulating evidence suggests that a favorable allograft outcome is associated with a robust population of $\mathrm{CD} 4^{+} \mathrm{CD} 25^{+} \mathrm{Foxp}^{+}$Tregs [23,24]. This particular Treg phenotype effectively suppressed alloactivation of recipient $\mathrm{T}$ cells in response to donor antigens in MLR assays and the activation and expansion of antigen-specific cells $[25,26]$, thus contributing to allograft immunity [27-29]. In our study, PrA-conditioned DGs in the tolerant state not only induced $\mathrm{T}$ cell hyporesponsiveness, but also expanded Tregs exhibiting donor antigen-specific immunosuppression. Moreover, PrA administration or infusion of PrA-pretreated DCs impaired T cell responses and induced Tregs in the spleen after transplantation. These recipient Tregs, but not third party Tregs, induced T-cell hyporesponsiveness (i.e., an alloantigen-specific response).

In a previous study, we found that $\operatorname{PrA}$ inhibited NF- $\kappa \mathrm{B}$ activation in grafts, resulting in reduced $\mathrm{T}$ cell proliferation in response to alloantigens [2]. Toll-like receptors (TLRs) play a major role in activating innate responses and directing adaptive immunity, including transplant immunity [30-32]. Toll-like receptor signals, especially signals activated by TLR4, lead to the rapid transcription of genes associated with inflammation. In APCs, TLR4 stimulation enhanced antigen presentation and upregulated costimulatory molecules [33]. Several recent studies have examined the role of TLR agonists and TLR signals in allorecognition, rejection, and tolerance. Walker et al.reported that blockade of the TLR/MyD88/NF- $\mathrm{B}$ pathway impaired DC function, rendering alloreactive $\mathrm{T}$ cells more susceptible to

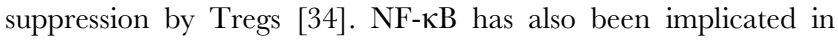
lymphocyte activation, proliferation, and survival of transplantation [30]. Consistent with our previous study, PrA suppressed TLR4 and NF- $\kappa \mathrm{B}$ expression and activation in DCs and thus likely reduced downstream responses to alloantigens.

The tolerogenic effect of PrA on DCs was further confirmed by changes in cytokine production. IL-12 is an inflammatory 
A
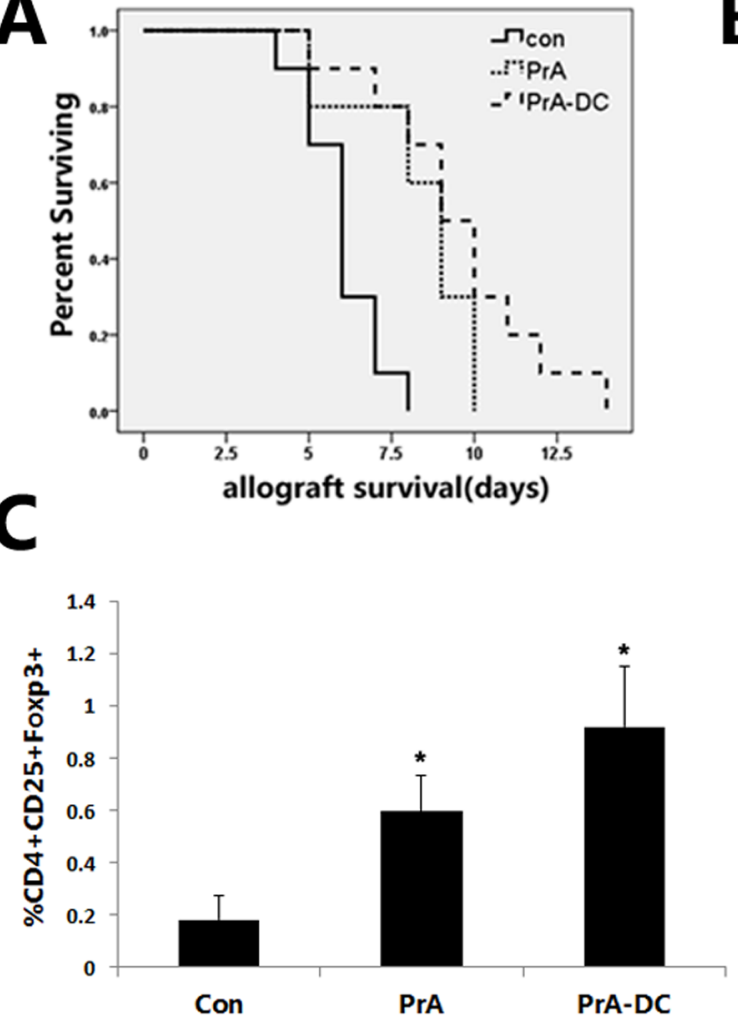

D

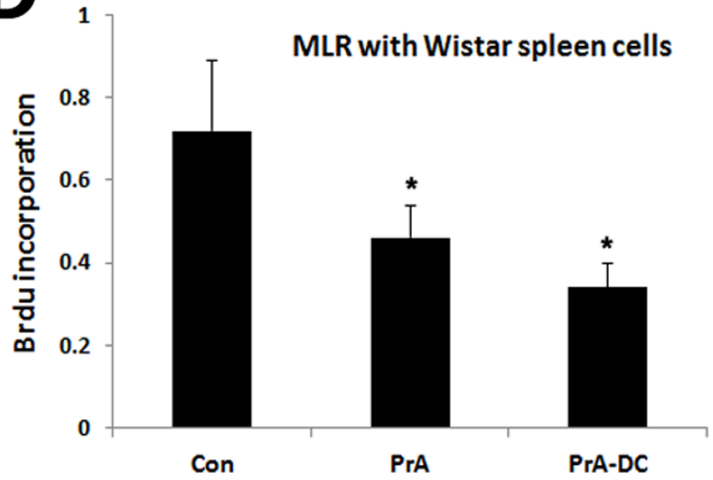

B
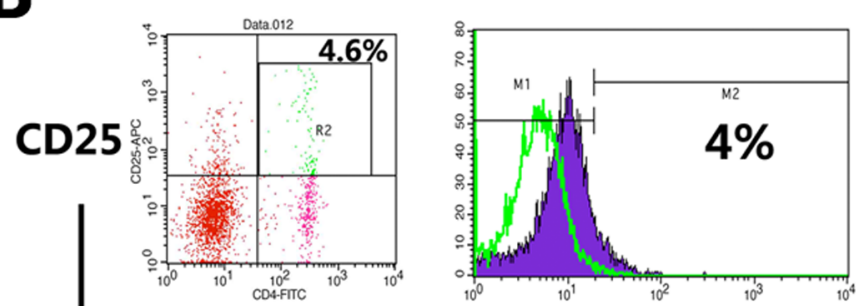

Con
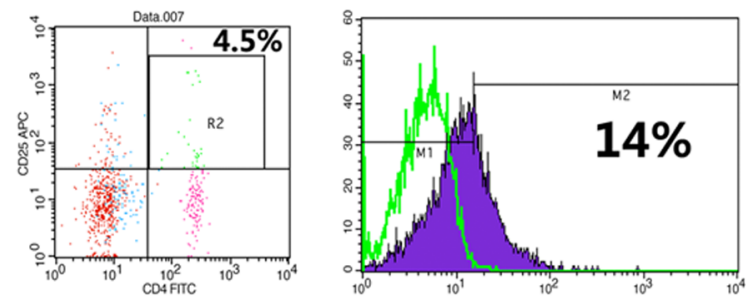

PrA

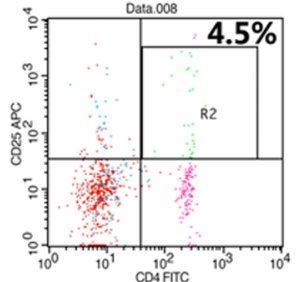

CD4

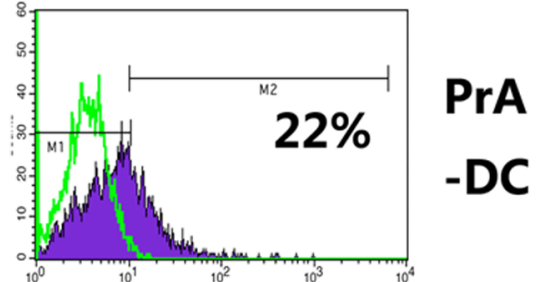

Foxp3
E

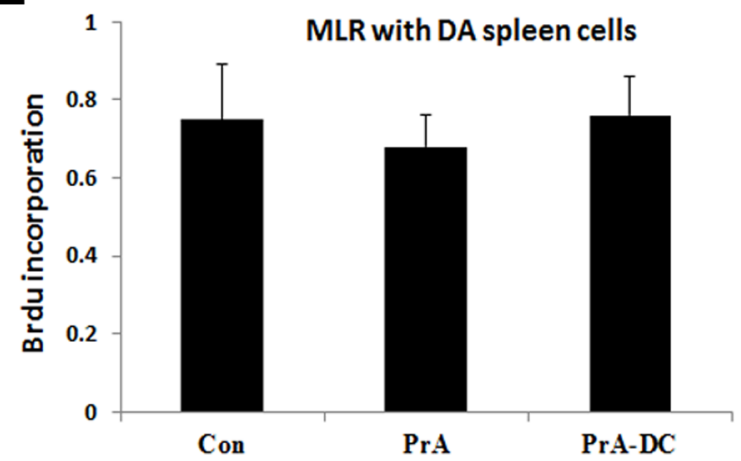

Figure 5. Both oral PrA and infusion of PrA-treated Wistar DCs prolonged allograft survival and expanded alloantigen-specific Tregs. (A) SD rats were transplanted with Wistar cardiac allograft and received different treatment posttransplantation. Infusion of PrA-treated DCs or oral PrA promoted cardiac allograft survival. Mean survival time was significantly longer for the PrA-treated DC group $(9.000 \pm 0.791$ days, $n=10)$ and PrA group ( $9.000 \pm 0.483$ days, $n=10)$ compared to the PBS-injected control group $(6.000 \pm 0.362$ days, $n=10)$. (B, C) At day 7 posttransplantation, $\mathrm{CD} 4^{+} \mathrm{CD} 25^{+}$populations were gated in recipient spleen lymphocytes and Foxp3 expression was observed by FACS. Both PrA and PrA-treated DC infusion expanded the $\mathrm{CD}^{+} \mathrm{CD} 25^{+} \mathrm{Foxp}^{+}$Treg population in spleen cells of recipient rats. (D, E) Both PrA treatment and PrA-treated DC infusion suppressed T cell proliferation in an alloantigen specific manner in recipient rats. On day 7, T cells isolated from SD recipient rats (responders) were mixed with donor Wistar spleen cells or third party DA spleen cells in MLRs and T cell proliferation assessed by Brdu incorporation. The results are means \pm SE of three independent experiments $(C-E ; n=3)$. Similar results were obtained in three independent experiments $(B ; n=3)$. ${ }^{*} P<0.05$ compared to LPS-treated PrA-naïve control DCs.

doi:10.1371/journal.pone.0066336.g005

cytokine, while IL-10 is a potent anti-inflammatory cytokine that suppresses alloimmunity and autoimmune responses [35,36]. Furthermore, IL-10 is a key factor in the expansion and differentiation of Tregs and can enhance the long-term maintenance of allografts in vivo [37,38]. PrA increased IL-10 production by DCs in a dose-dependent manner and sustained the function of donor rat heart in a transplant model. Thus, increased IL-10 release by DGs in response to PrA may mediate the induction of
Tregs in vitro and in vivo. However another suppressive cytokine [39], TGF- $\beta$ production was not affected by $\operatorname{PrA}$ in DCs culture or serum of recipient rats, suggesting that TGF- $B$ was not involved in the immunosuppressive mechanism of $\operatorname{PrA}$.

In conclusion, $\operatorname{PrA}$ may act by conferring a tolerogenic functional state on DGs that induces the expansion of alloantigen-specific Tregs, thereby reducing allograft immunity. We have identified the likely intracellular signals that mediate the immu- 

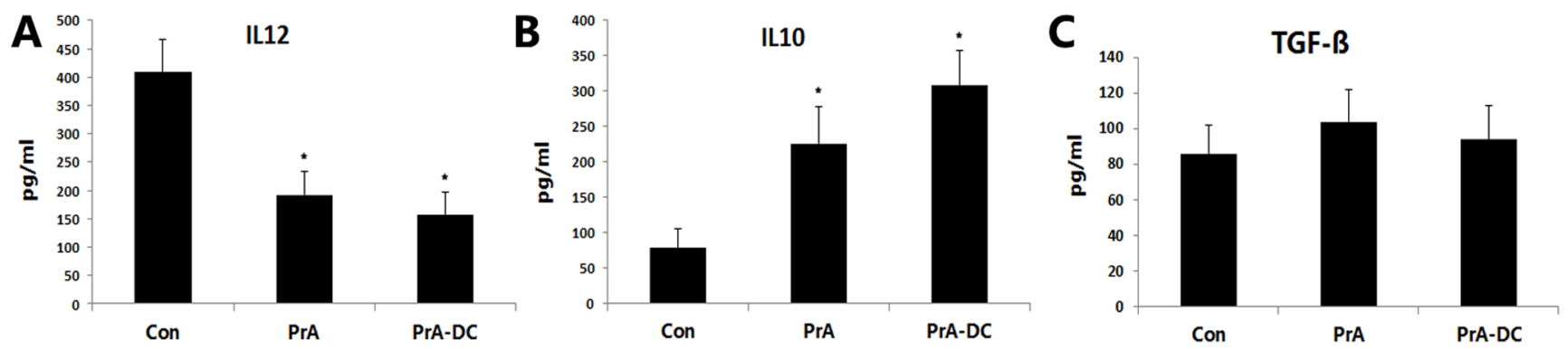

Figure 6. PrA modulated IL-10 and IL-12 production in vivo. Both PrA and PrA-treated DC infusion suppressed IL-12p70 production (A) and enhanced IL-10 production (B) in vivo as revealed by ELISAs of serum samples from recipient rats at day 7 posttransplantation. PrA showed no significant effect on TGF- $\beta$ production in serum of recipient rats (C). The results are means \pm SE of three independent experiments $(n=3)$. ${ }^{*} P<0.05$ compared to the PBS-injected control group.

doi:10.1371/journal.pone.0066336.g006

nosuppressive effect of $\operatorname{PrA}$ and provide strong support for the feasibility of PrA treatment as an immunotherapeutic strategy.

\section{Supporting Information}

Figure S1 Representative FACS result of sorted $\mathrm{CD}^{+} \mathrm{CD}^{+} 5^{+} \mathrm{T}$ cells purity by MACS.

(TIF)

\section{References}

1. Wu J, Hou JB, Zhang MM, Zou YP, Yu B (2008) Protosappanin a, an immunosuppressive constituent from a Chinese herb, prolongs graft survival and attenuates acute rejection in rat heart allografts. Transplant Proc 40: 3719-3722.

2. Wu J, Zhang M, Jia H, Huang X, Zhang Q et al. (2010) Protosappanin A induces immunosuppression of rats heart transplantation targeting $\mathrm{T}$ cells in grafts via NF-kappaB pathway. Naunyn Schmiedebergs Arch Pharmacol 381: 83-92.

3. Borges FT, Melo SA, Ozdemir BC, Kato N, Revuelta I, et al. (2012) TGFbeta1-Containing Exosomes from Injured Epithelial Cells Activate Fibroblasts to Initiate Tissue Regenerative Responses and Fibrosis. J Am Soc Nephrol.

4. Moreau A, Varey E, Beriou G, Hill M, Bouchet-Delbos L, et al. (2012) Tolerogenic dendritic cells and negative vaccination in transplantation: from rodents to clinical trials. Front Immunol 3: 218.

5. Yang H, Cheng EY, Sharma VK, Lagman M, Chang C, et al. (2012) Dendritic cells with TGF-betal and IL-2 differentiate naive CD4+ T cells into alloantigenspecific and allograft protective Foxp3+ regulatory T cells. Transplantation 93: 580-588.

6. Morelli AE, Thomson AW (2007) Tolerogenic dendritic cells and the quest for transplant tolerance. Nat Rev Immunol 7: 610-621.

7. Ezzelarab M, Thomson AW (2011) Tolerogenic dendritic cells and their role in transplantation. Semin Immunol 23: 252-263.

8. Thomson AW, Turnquist HR, Zahorchak AF, Raimondi G (2009) Tolerogenic dendritic cell-regulatory $\mathrm{T}$-cell interaction and the promotion of transplant tolerance. Transplantation 87: S86-90.

9. Zhang M, Wang Q Liu Y, Sun Y, Ding G, et al. (2004) Effective induction of immune tolerance by portal venous infusion with IL-10 gene-modified immature dendritic cells leading to prolongation of allograft survival. J Mol Med (Berl) 82: 240-249.

10. Lundsgaard D, Holm TL, Hornum L, Markholst H (2005) In vivo control of diabetogenic T-cells by regulatory CD4+CD25+ T-cells expressing Foxp3. Diabetes 54: 1040-1047.

11. Zhang M, Liu F, Jia H, Zhang Q Yin L, et al. (2011) Inhibition of microRNA let-7i depresses maturation and functional state of dendritic cells in response to lipopolysaccharide stimulation via targeting suppressor of cytokine signaling 1 . J Immunol 187: 1674-1683.

12. Shukla S, Gupta S (2004) Suppression of constitutive and tumor necrosis factor alpha-induced nuclear factor (NF)-kappaB activation and induction of apoptosis by apigenin in human prostate carcinoma PC-3 cells: correlation with downregulation of NF-kappaB-responsive genes. Clin Cancer Res 10: 3169-3178.

13. Ono K, Lindsey ES (1969) Improved technique of heart transplantation in rats. J Thorac Cardiovasc Surg 57: 225-229.

14. Lange C, Durr M, Doster H, Melms A, Bischof F (2007) Dendritic cellregulatory T-cell interactions control self-directed immunity. Immunol Cell Biol 85: $575-581$

15. Mahnke K, Johnson TS, Ring S, Enk AH (2007) Tolerogenic dendritic cells and regulatory T cells: a two-way relationship. J Dermatol Sci 46: 159-167.

\section{Acknowledgments}

We offer special thanks to International Science Editing for revision of the manuscript.

\section{Author Contributions}

Conceived and designed the experiments: MZ SZ JH BY. Performed the experiments: MZ JW LL JL. Analyzed the data: YS WD. Contributed reagents/materials/analysis tools: BY. Wrote the paper: MZ SZ JW. Collected the samples: LL JL WD.

16. Coquerelle C, Moser M (2008) Are dendritic cells central to regulatory T cell function? Immunol Lett 119: 12-16.

17. Schildknecht A, Brauer S, Brenner C, Lahl K, Schild H, et al. (2010) FoxP3+ regulatory $\mathrm{T}$ cells essentially contribute to peripheral CD8+ T-cell tolerance induced by steady-state dendritic cells. Proc Natl Acad Sci U S A 107: 199-203.

18. Beriou G, Peche H, Guillonneau C, Merieau E, Cuturi MC (2005) Donorspecific allograft tolerance by administration of recipient-derived immature dendritic cells and suboptimal immunosuppression. Transplantation 79: 969972.

19. Peche H, Trinite B, Martinet B, Cuturi MC (2005) Prolongation of heart allograft survival by immature dendritic cells generated from recipient type bone marrow progenitors. Am J Transplant 5: 255-267.

20. McCurry KR, Colvin BL, Zahorchak AF, Thomson AW (2006) Regulatory dendritic cell therapy in organ transplantation. Transpl Int 19: 525-538.

21. Hattori T, Saban DR, Emami-Naeini P, Chauhan SK, Funaki T, et al. (2012) Donor-derived, tolerogenic dendritic cells suppress immune rejection in the indirect allosensitization-dominant setting of corneal transplantation. J Leukoc Biol 91: 621-627.

22. Lutz MB, Suri RM, Niimi M, Ogilvie AL, Kukutsch NA, et al. (2000) Immature dendritic cells generated with low doses of GM-CSF in the absence of IL-4 are maturation resistant and prolong allograft survival in vivo. Eur J Immunol 30: 1813-1822.

23. Braudeau C, Racape M, Giral M, Louis S, Moreau A, et al. (2007) Variation in numbers of CD4+CD25highFOXP3+ T cells with normal immuno-regulatory properties in long-term graft outcome. Transpl Int 20: 845-855.

24. Cobbold SP (2008) Regulatory T cells and transplantation tolerance. J Nephrol 21: $485-496$.

25. Xia G, Kovochich M, Truitt RL, Johnson BD (2004) Tracking ex vivoexpanded CD4+CD25+ and CD8+CD25+ regulatory T cells after infusion to prevent donor lymphocyte infusion-induced lethal acute graft-versus-host disease. Biol Blood Marrow Transplant 10: 748-760.

26. Xia G, Truitt RL, Johnson BD (2006) Graft-versus-leukemia and graft-versushost reactions after donor lymphocyte infusion are initiated by host-type antigenpresenting cells and regulated by regulatory $\mathrm{T}$ cells in early and long-term chimeras. Biol Blood Marrow Transplant 12: 397-407.

27. Zhang X, Li M, Lian D, Zheng X, Zhang ZX, et al. (2008) Generation of therapeutic dendritic cells and regulatory $\mathrm{T}$ cells for preventing allogeneic cardiac graft rejection. Clin Immunol 127: 313-321.

28. Nishimura E, Sakihama T, Setoguchi R, Tanaka K, Sakaguchi S (2004) Induction of antigen-specific immunologic tolerance by in vivo and in vitro antigen-specific expansion of naturally arising Foxp3+CD25+CD4+ regulatory T cells. Int Immunol 16: 1189-1201.

29. Joffre O, Santolaria T, Calise D, Al Saati T, Hudrisier D, et al. (2008) Prevention of acute and chronic allograft rejection with CD4+CD25+Foxp3+ regulatory T lymphocytes. Nat Med 14: 88-92. 
30. Bonham CA, Peng L, Liang X, Chen Z, Wang L, et al. (2002) Marked prolongation of cardiac allograft survival by dendritic cells genetically engineered with NF-kappa B oligodeoxyribonucleotide decoys and adenoviral vectors encoding CTLA4-Ig. J Immunol 169: 3382-3391.

31. Schnare M, Barton GM, Holt AC, Takeda K, Akira S, et al. (2001) Toll-like receptors control activation of adaptive immune responses. Nat Immunol 2: 947-950.

32. Critchley WR, Fildes JE (2012) Graft rejection - endogenous or allogeneic? Immunology 136: 123-132.

33. Akira S, Uematsu S, Takeuchi O (2006) Pathogen recognition and innate immunity. Cell 124: 783-801.

34. Walker WE, Nasr IW, Camirand G, Tesar BM, Booth GJ, et al. (2006) Absence of innate MyD88 signaling promotes inducible allograft acceptance. J Immunol 177: 5307-5316.
35. Roncarolo MG, Gregori S, Battaglia M, Bacchetta R, Fleischhauer K, et al. (2006) Interleukin-10-secreting type 1 regulatory T cells in rodents and humans. Immunol Rev 212: 28-50.

36. Caretto D, Katzman SD, Villarino AV, Gallo E, Abbas AK (2010) Cutting edge: the $\mathrm{Th} 1$ response inhibits the generation of peripheral regulatory $\mathrm{T}$ cells. J Immunol 184: 30-34.

37. Battaglia M, Stabilini A, Draghici E, Gregori S, Mocchetti C, et al. (2006) Rapamycin and interleukin-10 treatment induces T regulatory type 1 cells that mediate antigen-specific transplantation tolerance. Diabetes 55: 40-49.

38. Huurman VA, Velthuis JH, Hilbrands R, Tree TI, Gillard P, et al. (2009) Allograft-specific cytokine profiles associate with clinical outcome after islet cell transplantation. Am J Transplant 9: 382-388.

39. Shen E, Zhao K, Wu C, Yang B (2011) The suppressive effect of CD25+Treg cells on Th1 differentiation requires cell-cell contact partially via TGF-beta production. Cell Biol Int 35: 705-712. 